\title{
"A cognitive model for managing the national innovation system parameters based on international comparisons (the case of the EU countries)"
}

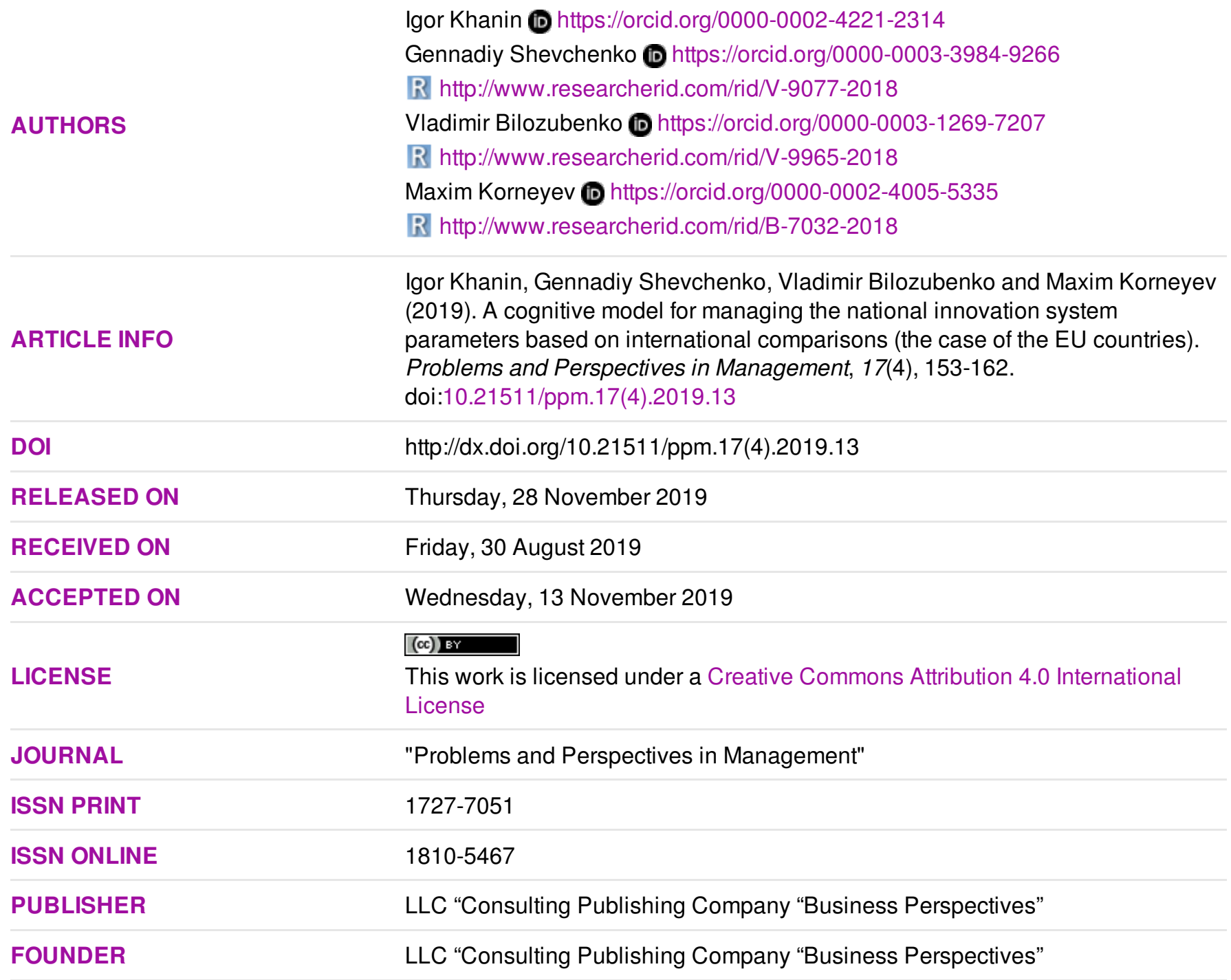

NUMBER OF REFERENCES

27
NUMBER OF FIGURES

1
NUMBER OF TABLES

2

(C) The author(s) 2023. This publication is an open access article. 


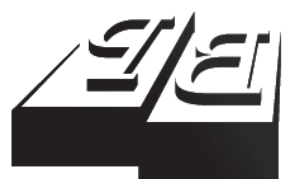

BUSINESS PERSPECTIVES

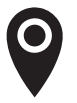

LLC "CPC "Business Perspectives" Hryhorii Skovoroda lane, 10, Sumy, 40022, Ukraine

www.businessperspectives.org

Received on: $30^{\text {th }}$ of August, 2019 Accepted on: $13^{\text {th }}$ of November, 2019

(C) Igor Khanin, Gennadiy Shevchenko, Vladimir Bilozubenko, Maxim Korneyev, 2019

Igor Khanin, Doctor of Economics, Professor, National University of Water and Environmental Engineering, Rivne, Ukraine.

Gennadiy Shevchenko, Candidate of Technical Sciences, Associate Professor, Association Noosphere, Dnipro, Ukraine.

Vladimir Bilozubenko, Doctor of Economics, Associate Professor, University of Customs and Finance, Dnipro, Ukraine.

Maxim Korneyev, Doctor of Economics, Associate Professor, University of Customs and Finance, Dnipro, Ukraine.

\section{(ㄷ)(i)}

This is an Open Access article, distributed under the terms of the Creative Commons Attribution 4.0 International license, which permits unrestricted re-use, distribution, and reproduction in any medium, provided the original work is properly cited.
Igor Khanin (Ukraine), Gennadiy Shevchenko (Ukraine), Vladimir Bilozubenko

(Ukraine), Maxim Korneyev (Ukraine)

A COGNITIVE MODEL

FOR MANAGING THE NATIONAL INNOVATION SYSTEM PARAMETERS BASED ON INTERNATIONAL COMPARISONS (THE CASE OF THE EU COUNTRIES)

\begin{abstract}
To carry out a comparative analysis of the EU countries' national innovation systems (NIS), a feature vector has been compiled, covering three modules, namely, science, education, and innovation. The feature vector is a valid multidimensional data set of sixteen official statistics indices and two sub-indices of the Global Innovation Index. The development of a cognitive model for managing the NIS parameters required a preliminary three-stage empirical study to determine its elements. In the first stage, cluster analysis was performed (the $\mathrm{k}$-means, metric - Euclidean distance algorithm was used). As a result, the EU countries were divided into four clusters (following multidimensional scaling estimates). In the second stage, a classification analysis (using decision trees) was carried out, which allowed determining three parameters that distinguish clusters (or classes) optimally. These parameters are recognized as important ones in terms of positioning the countries in the general ranking; that is, they can be considered as a priority for the NIS development and improving the countries' positions in international comparisons. In the third stage, based on the authors' approach, the significance (information content) of each key parameter is estimated. As a result, a cognitive model was compiled, taking into account the parameter significance. The model can be used in managing the NIS parameters, seeking to increase the system performance and improve the international position of a specific country. The model can also be used by partner countries, for example, Ukraine, as it demonstrates the landscape of EU innovative development and outlines the directions for priority development of NIS towards the European progress.
\end{abstract}

\section{Keywords}

innovation performance, cluster, informativeness, cognitive model, management

\section{JEL Classification C38, F00, O11, O57}

\section{INTRODUCTION}

In the contemporary economic paradigm, innovation has become one of the main factors for sustainable growth and competitiveness. Their intensive development and implementation requires a systematic approach in the innovation sector, which manifests itself in creating the national innovation systems (hereinafter NIS). The economy dynamism and transformation necessitate the continuous maintenance of the NIS performance and development; this implies proper management of this system.

NIS is a complex thing including different subsystems and blocks, which are described by a wide range of special parameters (hereinafter, along with the "parameter" term, its synonyms will be used, 
namely, feature, indicator, characteristic, attribute), which are in a close but hard-to-explain relationship. Because of this, subjective empirical and heuristic approaches and widespread economic and mathematical models of NIS management prevailing today are ineffective within the innovation policy framework. Therefore, the crucial task is to develop new scientifically-based approaches and models for managing the NIS parameters that can ensure high-quality decisions with the permissible complexity of manipulating the available data. This problem can be solved by developing a unique cognitive model that more adequately describes the correlation of NIS parameters and targets the innovation policy tools. Drawing up a cognitive model should be based on separating key parameters, which allows focusing the resources on the main areas. It is possible to identify such a group by comparing the NISs of different countries using clustering and classification analysis.

In the European Union, great attention is paid to improving the performance and development of NIS. It is worth noting that regular international comparisons are carried out in the EU states (for example, the European Innovation Scoreboard) to comparatively analyze the innovation performance. For each EU member state, given the existing order, it is essential to improve its position in the EU ranking, acting within the framework of the basic strategic course and the global consolidation goals. The proposed cognitive model of managing the NIS parameters will facilitate a solution to the problem. The case of the EU countries is of interest to other states in terms of more rational use and selective increase of innovative potential.

\section{LITERATURE REVIEW}

At country level, NIS is designed to ensure the initiation, creation, and application of innovations, the unification of various actors' roles (universities, research institutes, large companies, SMEs, innovation infrastructure, non-governmental organizations, authorities), as well as broad support for innovation in all economy sectors (Freeman, 1987; Lundvall, 1992; Nelson, 1993; Patel \& Pavitt, 1994). This article parametrically describes three main NIS modules: science (research and development), education (higher education), and innovation (innovative business activities). The need to include higher education corresponds to the gradual evolution of modern ideas about NIS (Radosevic \& Petraite, 2006). Such an approach correlates with the Triple Helix model, which symbolizes the alliance of business, universities and government (Etzkowitz, 2011). Ranga and Etzkowitz (2013) consider the Triple Helix as a conceptual and analytical construction describing the special nature of interaction among universities, industry and government in the innovation system (hereinafter, the fourth helix began to stand out, namely, civil society; then the fifth helix, habitat, emerged).

The role of higher education in the NIS is considered in more detail in the Knowledge
Triangle concept, which is a systematic view of the relationship among research (knowledge generation), education (knowledge dissemination and human capital training) and innovation (business innovation) (Unger \& Polt, 2017). Knowledge Triangle characterizes the interaction of actors such as academic institutions, educational institutions and private companies. Knowledge Triangle has not yet been proved in practice; however, it shapes a new look at the NIS functional structure (Lassnigg, Hartl, Unger, \& Schwarzenbacher, 2017). For example, this concept is beneficial for ensuring the innovative development of the economic sectors, explaining the roles of each of the modules (Smol \& Kulczycka, 2019).

The NIS management, which is essential for improving the performance and development, has become a part of modern state innovation policy (Patel \& Pavitt, 1994; Edler \& Fagerberg, 2017). This management is only possible via quantitative assessment (parameter measurement) of the system and in many cases, involves a complex effect on individual indicators or groups of indicators describing its modules. However, this is complicated by a broad set of such parameters, which limits the possibilities of substantiating and targeting the innovative policy measures (Patel \& Pavitt, 1994; Edler \& Fagerberg, 2017). 
The targeted management of NIS, meanwhile, becomes especially important in the context of globalization, when accelerated results in international rivalry with limited resources and fierce innovation race are required. In this regard, cross-country comparisons are becoming an integral part of both the analysis and practical management of NIS.

A few decades ago, the EU, uniting 28 European countries with different rates of economic and innovative development, switched to a common scientific and technological policy, and in recent years, formed a unified approach to the innovation development. The actual progress of the EU is achieved through the commitment of all member countries to the strategic course, their activity and general convergence. This means that each country needs to act effectively in the field of NIS development, increasing its functional parameters in the context of the pan-European process. This task is not only intra-European, but it is also of global importance to surpass other world leaders in terms of innovation performance, which is defined and evaluated in the European Innovation Scoreboard. This is of particular interest for the Central and Eastern European countries, which have begun or are only entering on the path of European integration, join the EU initiatives and structures in the field of innovation, experience special problems in the NIS creation and management.

The NIS management, based on the detailed description and quantitative evaluation of innovation performance parameters, is performed both by individual member countries and at the EU level (Janger, Schubert, Andries, Rammer, \& Hoskens, 2017; Pegkas, Staikouras, \& Tsamadias, 2019). Of particular interest is the NIS management for developing countries seeking to form and ensure the sustainable functioning of NIS (Casadella \& Uzunidis, 2017). In this regard, one can emphasize the Mehta's (2018) work on the innovation system of India. The author, among other things, focuses on the difficulties of determining the main characteristics that reflect the functioning of such a system and can be used to control it (Mehta, 2018). In this context, the current study outlines a non-trivial way of highlighting the critical NIS features and establishing causal relationships among them, which are required for compiling the models.

Cognitive models (maps) are offered as such a way; they are widely used to analyze and introduce complex causal relationships in computer science, medicine, biology, geography, environmental science, behavioral and social sciences, business, economics, i.e., in the soft knowledge areas (Kosko, 1986; Papageorgiou \& Salmeron, 2013), followed by the use of the analysis findings to build NIS management techniques. Many studies confirm the possibilities of effective application of cognitive models (maps) in various research areas, for example, Shas. Gupta and Shal. Gupta (modeling economic system) (2017); Ginis (analysis of structure of social and economic system for the purpose of its sustainable development) (2015); Carvalho and Tomé (modeling of qualitative socio-economic systems) (2009);Penn et al. (establishment of a bio-based economy in the Humber region) (2013); Yatsukh (modeling of factors of influence on the processes of formation and reproduction of fixed assets of enterprises) (2018); Kozmenko and Kuzmenko (modeling of reinsurance flows on the global reinsurance market) (2017); Vidal, Salmeron, Mena, and Chulvi (to develop eco-innovation) (2015). It is advisable to expand the use of cognitive models and other similar tools to increase the performance of universities' innovative activities (Y. Petrunia, Chentsov, Życzyński, \& V. Petrunia, 2019).

The analysis allows, firstly, talking about the relevance of managing the NIS parameters to ensure its performance and development. The correct choice of critical metrics that compose the management model, is paramount for solving the problem of the NIS parameter management. Secondly, academic research and practice confirm the applicability of cognitive models (maps), which become a specific tool in making decisions. The development of a cognitive model in the EU context will be of particular interest both for the member states, where the emergence and establishment of an international innovation system are observed, and other countries, in which the EU development pathways and experience are studied. In practice, selecting key parameters and compiling a cognitive model on their basis for managing the NIS parameters remain an unsolved task. 
Given the NIS structure complexity, its extensional understanding is needed, involving science, education and innovation, which shapes the multifactor nature of the NIS empirical assessment. The study proceeds from the fact that the indicators (parameters) are a priori informative and related. The main hypotheses for choosing parameters to compile a cognitive model for managing the NIS parameters are: 1) the hypothesis of the systematic and inertia less functioning of such systems, which is displayed by the parameters and makes parametric control possible; 2) the hypothesis of horizontal equality and universality (for countries) of all the NIS components without taking into account their interaction; and 3) the hypothesis of the control appropriateness based on a relatively small number of parameters (selecting key parameters from the totality).

\section{RESEARCH PURPOSE}

The study focuses on selecting the most significant (key at a given time) parameters from the presented feature vector of the EU countries' NIS and developing a cognitive model for managing the NIS parameters.

The research object is the EU countries, which have significant differences in the innovation intensity and, consequently, the NIS performance. The European Innovation Scoreboard divides countries into four groups (modest innovators, moderate innovators, strong innovators, and innovation leaders); that is, there is a particular country rating. Therefore, the proposed cognitive model can be used by lagging countries to improve their positions, by leading ones to maintain their positions, and on the whole, for the general convergence of innovation performance indicators. This is the main practical value of the authors' approach for any ratings.

The parameter (attribute) $x$ means a discrete description (transformed from the quantitative or qualitative one) of a certain feature of the studied object $X$ - NIS, which allows for further structuring many NIS objects of different countries, highlighting the basic elements, which characterize their development, and building a mechanism for managing such systems.

\section{EMPIRICAL BASE AND MODEL PARAMETERS SELECTION}

First of all, it is necessary to compile a common set of parameters for describing and evaluating NIS (it is assumed that each NIS object $X$ is described using a set of attribute values $x_{1}, \ldots, x_{n}$, i.e., represented by a point in the feature space with the $n$ dimension, with the values of these features along its axes), this is the feature space. A description of an object $X$ is seen as a set $X=\left(x_{1}, x_{2}, \ldots, x_{n}\right)$ of discrete values of features, which will be called simply a discrete set of $X$. The authors form such a complex based on a synthesis of official statistics and international indices (including their components), structurally involving science, education and innovations; a reference is made to the fact that in the NIS functioning, they are a single whole and complement each other. To date, the interaction of the parameters of these sectors and the parallelism of changes are not in doubt. However, indicating this and even confirming this in practice does not mean understanding; therefore, the operating principle of a complex entity such as NIS remains to be understood. This will be the aim of further analysis and modeling.

A structured set of features available for evaluation contains a higher amount of information than each of them individually. This allows searching for a comprehensive and more effective solution. Moreover, the selection of key parameters is essential, which has a more focused effect and is based on assessing the informational content (informativeness) of both the whole sample and each parameter.

NIS is an infinitely complex object; it can only be described by innumerable features, attributes, and characteristics. With that, awareness of this object in each stage is relative and finite. To conduct the study, a set of indicators of official statistics and international indices was formed, which became a feature vector of the NIS (see Table 1).

The resulting sample includes both quantitative and qualitative (ordinal) parameters. They are heterogeneous and specific, reflect significant characteristics, and explain various elements and pro- 
Table 1. A feature vector of the EU countries' NISs, structuring its parameters according to the three main modules

Source: SCImago Journal \& Country Rank, World Intellectual Property Organization, The World Bank Group, Eurostat, Global Competitiveness Report (2018), Human Development Report (2018), INSEAD.

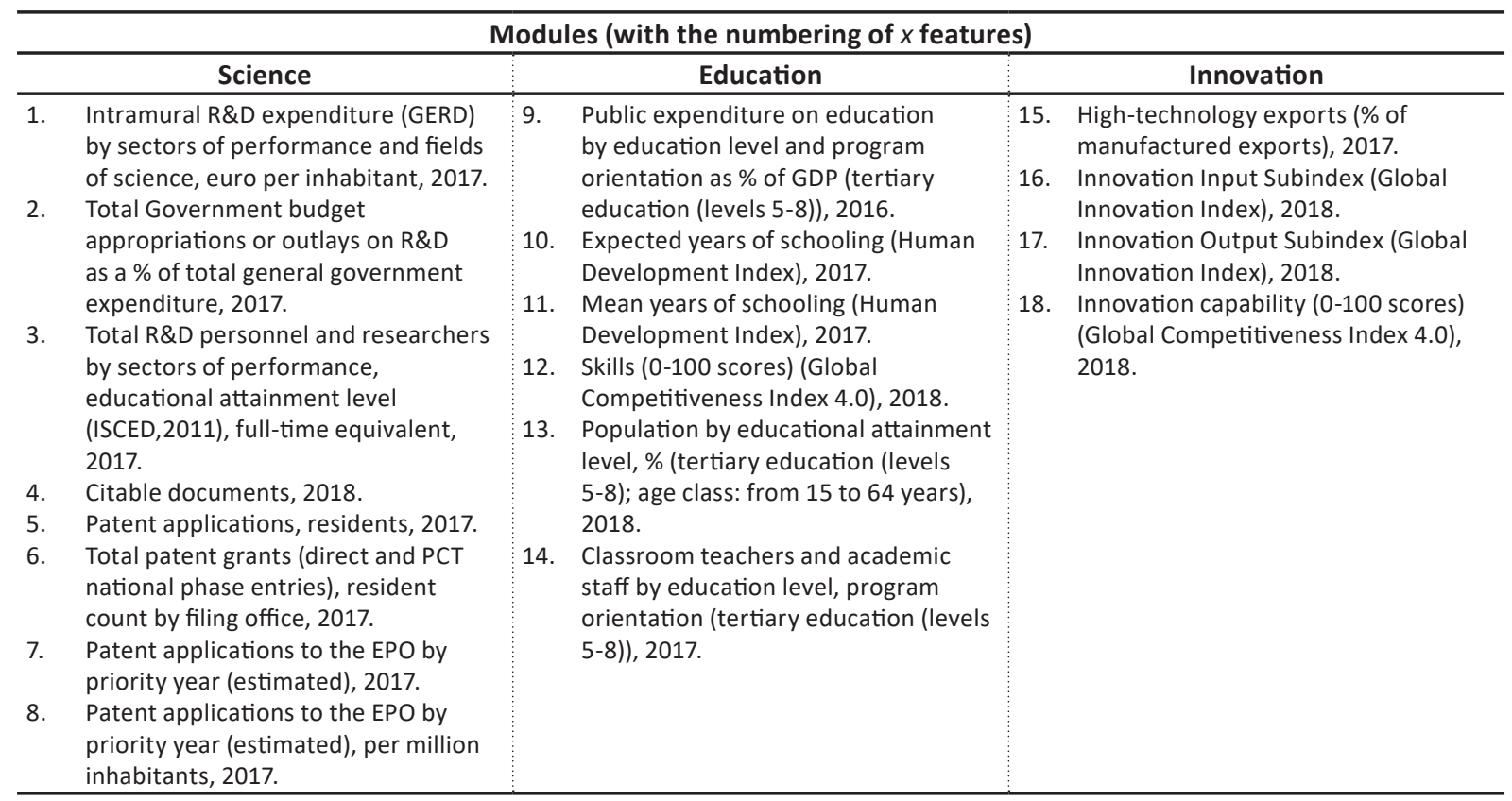

Note: In several cases, preliminary data from relevant sources are provided. In the cells where there were no 2017 $(2016,2018)$ data, official figures for previous years are used.

cesses of the NIS operation. All Table 1 indicators are controllable (NIS is considered as a complex and holistic object with high self-organization, but which may be affected; links between elements remain unchanged when the system changes).There are no incompatible indicators and such parameters in which saturation is possible. Indices (estimates) are of particular importance, which has an upper limit but should also seek to increase.

Problem statement for the parameter selection. Managing the NIS performance and development, taking into account the data in Table 1 , is focused on how countries move into a cluster of more successful states (and how leaders hold their positions).With limited resources, it is not possible to manage all parameters simultaneously. Therefore, it is first necessary to concentrate efforts and resources on a relatively limited number of key parameters. The selection of these parameters makes managerial actions expedient, gives a certain accuracy and makes practical sense in relation to a complex system such as NIS.

To assess the structure of the existing landscape by country, represented by a data set, and to define the positions of individual states relative to others, a cluster analysis is used. To specify the differences between the objects of different clusters, a classification analysis will be applied, which will emphasize the parameters that divide (distinguish) all clusters and, therefore, can be considered as key for this parameter set in terms of changing countries' positions in the broad scale.

Stage 1 in the parameter selection: a cluster analysis. To assess the structure of the existing NIS landscape by country, a data set is presented. This set is an "object-property" table (OPT); that is, a table where rows are objects and the columns are objects' properties. To analyze these data, a cluster analysis is proposed, which makes it possible to emphasize "similar" countries united in clusters and determine the positions of countries relative to each other accurate to the cluster. To determine the differences between the countries that are objects of different clusters (taking into account their description and presentation in the OPT as some objects), a classification analysis will be used, since the clusters found in the previous stage represent some classes, and the OPT, taking into account such structuring, evolves into a training sample 
(TS). Such an approach makes it possible to single out those parameters that divide (distinguish) all class clusters and which, therefore, can be considered as key for this parameter set in terms of controlling the change in the countries' positions in their ranking fixed at a measured time. Based on the specifics of the available data set, the k-means algorithm (metric is the Euclidean distance) was used for cluster analysis (Everitt, Landau, Leese, \& Stahl, 2011).

Cluster analysis was carried out according to official statistics and international indices presented in the form of OPT and with covering the Table 1 indicators. Previously, given three-dimensional visualization, which is based on the multidimensional scaling procedure, and many other calculated rates, the optimal number of clusters, four, was determined. This approach to determining the number of clusters and further clustering was implemented based on data mining tools available on ScienceHunter (http:// sciencehunter.net). The country clusters are presented in Table 2.

Table 2. The resulting country clusters according to the NIS parameters

\begin{tabular}{c:c}
\hline Cluster & \multicolumn{1}{c}{ Country } \\
\hline I & United Kingdom, Germany, France \\
\cline { 1 - 2 } II & $\begin{array}{l}\text { Austria, Belgium, Denmark, Ireland, Netherlands, } \\
\text { Finland, Sweden }\end{array}$ \\
III & Bulgaria, Hungary, Greece, Spain, Italy, Poland, \\
& Portugal, Romania, Croatia, Czech Republic \\
IV & Cyprus, Latvia, Lithuania, Luxembourg, Malta, \\
& Slovakia, Slovenia, Estonia \\
\hline
\end{tabular}

Stage 2 in the parameter selection: a classification analysis. Significance and key parameters for control purposes were assessed and identified based on classification analysis methods. Such methods make it possible to see the leadership architecture and country effectiveness according to NIS parameters and, thereby, create opportunities for strong managerial impact on the indicators that are the most important in this respect. Clustering confirmed the objectivity of the country grouping, so the task was further to find differences between clusters (groups of countries). Classification processing, in turn, allows distinguishing the parameters by which all clusters are distinguished and which determine the position of each country in the general rating.
For classification processing, logical and combinatorial methods for processing the data were used, presented as TS and allowing for quantitatively evaluating the information content of both individual parameters and their arbitrary groups. Besides, these techniques make it possible to determine those indicating significant differences between the found clusters (classes). The TS is presented as an empirical data table, consisting of many discrete sets of $X$, for each of which, belonging to a particular class is presented in this sample. The contribution of individual parameters can be estimated as follows:

$$
V\left(x_{i 1}, \ldots, x_{i j}\right)=\frac{1}{k} \sum_{\Delta \in \Gamma} \max _{Y}\left(\frac{m_{\Delta Y}}{m_{Y}}\right),
$$

where $k$ is the number of classes (clusters), $m_{Y}$ is the number of objects belonging to class (cluster) $Y, \Delta=t_{i 1}, t_{i 2}, \ldots, t_{i j}\left(0 \leq t_{i j} \leq k_{i j}-1\right), j=1, \ldots, \Gamma$ mean the arbitrary set of parameter values $x_{i 1}, \ldots, x_{i j}(1 \leq \Gamma \leq n), m_{\Delta Y}$ denotes the number of sampling sets of the $m$ class, for which the relation $x_{i j}=t_{i j}(j=1, \ldots, \Gamma)$ is performed, $t_{i i j}$ are the values of parameters $x_{i j}$ in the set of $\Delta$, $\Gamma$ means variety of all sets of parameter values $x_{i 1}, \ldots, x_{i j}$.

It can be shown that $1 / k \leq V\left(x_{i 1}, \ldots, x_{i j}\right) \leq 1$. With complete distinguishability of classes, this estimate assumes a limit value of 1 . It is crucial that such an estimate is calculated based directly on the TS data and characterizes its distinctive ability.

In the data set presented, 18 parameters characterizing NIS are used. Therefore, in the limiting case, even when using only binary data coding necessary to simplify the TS classification processing, a comprehensive search for groups of key parameters would require verification $2^{18}$ (i.e., over a quarter million) of different parameter combinations. Thus, it is important to find informative groups of attributes (IGA); this partly solves the problem of finding key metrics and reduces the total enumeration of parameters.

The study has proposed the search IGA procedure, based on the use of estimates (formula (1)) and implemented through a Science Hunter (http:// sciencehunter.net) portal. When processing the Table 1 data, an IGA was obtained, i.e. a group of 
parameters that can be key, since their values differ significantly among countries that are in different clusters, which include $x_{9}, x_{14}$ and $x_{18}$ parameters. Thus, they can be priorities in managing the NIS parameters.

Stage 3: determining the value of the NIS key parameters. There were several key parameters in the IGA. Therefore, it is advisable to establish priority (structural subordination) between them to ensure good governance in resource-poor settings. Significance is explained by how much the state of the object depends on them, i.e., the country's affiliation to a particular cluster. This means that the contribution of individual parameters to the estimate (formula (1)) is important. This makes it possible to have a deeper understanding in terms of control.

According to formula (1), the contribution of each parameter to the total informativeness component of the initial set of attributes included in the IGA was evaluated. That allowed evaluating their separation ability in that respect.

According to the IGA, which includes the $x_{9}, x_{14}$, $x_{18}$ (see Table 1) parameters, based on formula (1), the following results are obtained:

$$
\begin{gathered}
W\left(x_{18}\right)=0.68 ; W\left(x_{9}\right)=0.62 ; \\
W\left(x_{14}\right)=0.61 .
\end{gathered}
$$

Having normalized data with respect to the total value of estimates, the relative contributions of the parameters are obtained:

$$
\begin{gathered}
W *\left(x_{18}\right)=0.36 ; W^{*}\left(x_{9}\right)=0.32 ; \\
W^{*}\left(x_{14}\right)=0.32 .
\end{gathered}
$$

Thus, key parameters are first selected from the NIS assessment data set, and then the significance of each of them in this group is determined. This can serve as a reliable measure for targeting and decision making.

It is apparent that the $x_{18}$ "Innovation capability" parameter (Global Competitiveness Index 4.0) best contributes to the overall distinguishing ability of the entire IGA parameter group. Then, the $x_{9}$ parameter "Public expenditure on education by education level and program orientation as a $\%$ of
GDP (tertiary education (levels 5-8))," and parameter $x_{14}$ "Classroom teachers and academic staff by education level, program orientation, gender and age groups (tertiary education (levels 5-8))."

\section{GENERAL EXPLANATIONS OF THE MODEL DEVELOPMENT}

To manage the NIS parameters, a cognitive model was chosen, which should determine the correlation of key parameters previously determined. The preference for the cognitive model is due not only to the desire to test this approach in managing the NIS development, given that traditional formal quantitative models do not give the desired results, but also for the following reasons: 1) the presence of non-strict causal relationships; 2) the inability to directly achieve the goal (it is necessary to influence a complex system, which requires an additional special mechanism); 3) the variability of complex systems, the stochastic nature and variability of relations between its elements; 4) lack of information, lack of single correct value of indicators; 5) the need to complement the "technical" management of experience, decision flexibility and testing of different options in achieving target indicator levels; 6) the presence of too extensive range of means and actions, the absence of a single mechanism for their implementation and understanding of how they will change the situation (result).

Given the above, cognitive models take high priority over, for example, statistical models, which mainly determine a "strict" relationship between parameters, and do not always give the expected results. This draws attention to cognitive models as control models, which allow, in light of the above limitations, obtaining more perceptible and practical solutions. That is, cognitive models are a management tool, as they make it possible to operate with measurable parameters, albeit of varying accuracy degrees, and achieve the desired result, namely, changes in the general state or position of the system.

The current cognitive model for the NIS parameter management includes the following key pa- 


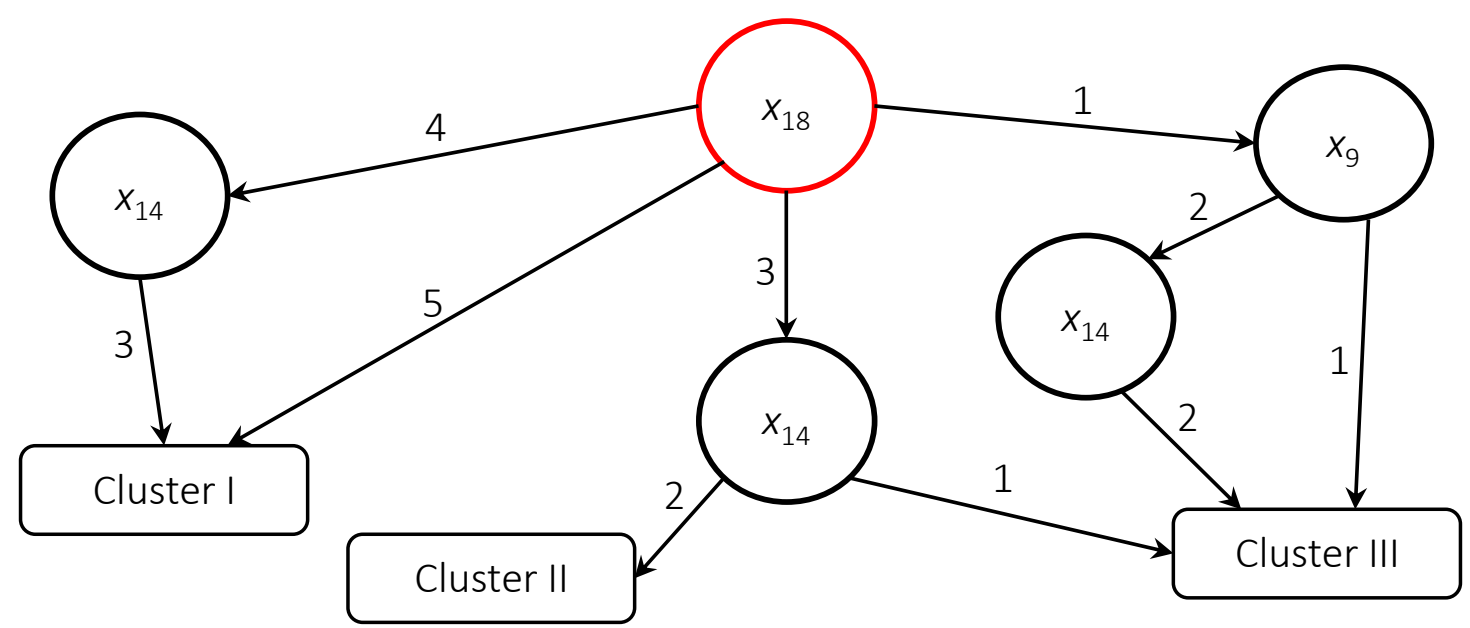

$x_{9}$ - "Public expenditure on education by education level and program orientation as a \% of GDP (tertiary education (levels 5-8))", $x_{14}$ - "Classroom teachers and academic staff by education level, program orientation, gender and age groups (tertiary education (levels 5-8))", $x_{18}$ - "Innovation capability" (Global Competitiveness Index 4.0).

Figure 1. Cognitive model for managing the NIS parameters of the EU countries

rameters: $x_{18}$ "Innovation capability" (Global Competitiveness Index 4.0), $x_{9}$ "Public expenditure on education by education level and program orientation as a $\%$ of GDP (tertiary education (levels 5- 8))" and $x_{14}$ "Classroom teachers and academic staff by education level, program orientation, gender and age groups (tertiary education (levels 5-8))." One should note that a total of several IGAs were found. This means several almost equivalent groups of key parameters. To simplify the presentation, the authors stayed with one of them (the relationship between the IGA can be the subject of a special analysis).

Managing the change in key parameters makes it possible to change the position of the innovation system of a particular country in a certain amount of steps. Based on the results of the TS processing via ScienceHunter portal (http://sciencehunter.net) and the set of key parameters found, one can now present the cognitive model as a diagram (Figure 1). The figures above the arrows and above the arcs indicate the effort, estimated in arbitrary units (1 to 5), that must be taken to achieve the desired result, for example, to make cluster I or II or III (the required level of effort is determined by discretization). According to the value assessment, $x_{18}$ is the reference point. The maximum 5 -unit forces (effects) must be applied to it, which can ensure getting into class I. If the forces are 4 , then, based on $x_{14}$, additional forces of 3 units will be required. To come over to class II, the following is needed: to move to $x_{18}$, one needs to make an effort of 3 units, to $x_{14}$ 2 units, etc. The same can be made for other classes by tracking the corresponding paths.

The resulting model summarizes the empirical data and describes the relationship between key parameters, i.e., effort concentration points. It eliminates inaccuracies in planning and makes actions more focused. Therefore, the model can be understood as a tool for managing the NIS parameters and be converted into effective management decisions, and then into economic achievements; one can compensate for the lag in most indicators by successes in key ones.

The cognitive model is focused, change-oriented and provides a synthesis of processes. It must be turned into a road map, that is, to outline measures for the national scientific, technical, educational and innovative policies. NIS is a complex control object with specific structural and functional characteristics. Therefore, one needs a longterm approach and special sound techniques in the form of additions to the presented cognitive model, namely, monitoring procedures, change control, result verification, expert support, statistical tools (integral indices, quality assessment and component development coordination); shortand medium-term scheduling; substantiating and considering the performance criteria. Expert support is also necessary (the resulting model does not exclude the consideration of the experts' opin- 
ions). It should also take into account the model shortcomings, namely the answer ambiguity and often the lack of understanding of the laws by which it operates. Among the basic principles of applying the obtained cognitive model in practice, the following are emphasized: taking into account the multivariance and context; an integrated approach (selected key parameters will work best in synergy); ensuring the continuity, given the NIS evolution (linking tactical actions into a single strategic line); accounting for external additions.
It should be noted that not only EU countries, but also partner countries, for example, Ukraine, could effectively apply the model. Clustering and classification analysis demonstrate the landscape of innovative development of the whole EU. It enables selecting the countries with the experience of particular interest. The selection of the key parameters outlines the directions for priority development of Ukraine's NIS towards the European progress for gradual achievement of target indicators.

\section{CONCLUSION}

The proposed scientific and methodological approach allowed emphasizing key parameters that best distinguish the country clusters obtained from the generated data set (attribute space) for the EU NIS assessment. The selection and evaluation of the value of each of the key parameters are of practical importance for the NIS management, because it allows focusing on the main areas and targeting the innovation policy measures. Based on the selected indicators, a cognitive model of NIS parameters management has been compiled. The model develops actions to build up key parameters to move a particular country to a more successful cluster. The proposed model can also be considered as an analytical tool to identify the NIS problems of individual countries and evaluate the effectiveness of innovative policy measures. Further research suggests 1) identifying ways to verify the adequacy and effectiveness of the cognitive model, to interpret its conclusions; 2) developing a methodological framework for managing the NIS parameters based on cognitive models taking into account available resources; and 3) formulating strategic aspects of applying such models for NIS management in the long term.

\section{REFERENCES}

1. Carvalho, J. P., \& Tomé, J. (2009). Rule Based Fuzzy Cognitive Maps in Socio-Economic Systems (Proceedings of the Joint 2009 International Fuzzy Systems Association World Congress and 2009 European Society of Fuzzy Logic and Technology Conference (1821-1826)). Lisbon. Retrieved from https://www.researchgate. net/publication/221399050_Rule_ Based_Fuzzy_Cognitive_Maps_ in_Socio-Economic_Systems

2. Casadella, V., \& Uzunidis, D. (2017). National Innovation Systems of the South, Innovation and Economic Development Policies: A Multidimensional Approach. Journal of Innovation Economics, 2(23), 137-157. Retrieved from https://ideas.repec.org/a/cai/ jiedbu/jie_pr1_0007.html

3. Edler, J., \& Fagerberg, J. (2017). Innovation policy: what, why, and how. Oxford Review of Economic
Policy, 33(1), 2-23. https://doi. org/10.1093/oxrep/grx001

4. Etzkowitz, H. (2011). The Triple Helix: University-industry-government innovation in action. Papers in Regional Science, 90(2), 441-442.

5. Everitt, B., Landau, S., Leese, M., \& Stahl, D. (2011). Cluster Analysis. John Wiley \& Sons Ltd.

6. Freeman, C. (1987). Technology and Economic Performance: Lessons from Japan. London, New York: Frances Printer Publishers.

7. Ginis, L. A. (2015). The Use of Fuzzy Cognitive Maps for the Analysis of Structure of Social and Economic System for the Purpose of Its Sustainable Development. Mediterranean Journal of Social Sciences, 6(3), 113-118. http:// dx.doi.org/10.5901/mjss.2015. v6n3s5p 113
8. Gupta, Shas., \& Gupta, Shal. (2017). Modeling Economic System Using Fuzzy Cognitive Maps. International Journal of System Assurance Engineering and Management, 8(2), 1472-1486. Retrieved from https://link.springer.com/ article/10.1007/s13198-017-0616-6

9. Janger, J., Schubert, T., Andries, P., Rammer, Ch., \& Hoskens, M. (2017). The EU 2020 innovation indicator: A step forward in measuring innovation outputs and outcomes? Research Policy, 46(1), 30-42. https://doi.org/10.1016/j. respol.2016.10.001

10. Kosko, B. (1986). Fuzzy Cognitive Maps. International Journal of Man-Machine Studies, 24(1), 65-75. https://doi.org/10.1016/ S0020-7373(86)80040-2

11. Kozmenko, O., \& Kuzmenko, O. (2017). Cognitive modeling of reinsurance flows on the global rein- 
surance market. Geopolitics under Globalization, 1(1), 5-11. https:// doi.org/10.21511/gg.01(1).2017.01

12. Lassnigg, L., Hartl, J., Unger, M., \& Schwarzenbacher, I. (2017). Higher Education Institutions and Knowledge Triangle: Improving the Interaction between Education, Research and Innovation HIS (Sociological Series. Working Paper, 118). Retrieved from https:// irihs.ihs.ac.at/id/eprint/4228/1/ rs118.pdf

13. Lundvall, B.-A. (1992). National Systems of Innovation: Towards a theory of innovations and interactive learning. London and $\mathrm{New}$ York: Pinter.

14. Mehta, S. (2018). National Innovation System of India: An Empirical Analysis. Millennial Asia, 9(2), 203-224. https://doi.org /10.1177\%2F0976399618786343

15. Nelson, R. (1993). National System of Innovation: A Comparative Analysis. Oxford University Press.

16. Papageorgiou, E. I., \& Salmeron, J. L. (2013). A Review of Fuzzy Cognitive Maps Research During the Last Decade. IEEE Transactions on Fuzzy Systems, 21(1), 66-79. Retrieved from https://ieeexplore. ieee.org/document/6208855

17. Patel, P., \& Pavitt, K. (1994). National Innovation Systems: Why They Are Important, and How They Might Be Measured and Compared. Journal Economics of Innovation and New Technology, 3(1), 77-95. https://doi. org/10.1080/10438599400000004

18. Patel, P., \& Pavitt, K. (1994). The Nature and Economic Importance of National Innovation Systems.
STI Review, 14, 56-68. Retrieved from https://www.econbiz.de/ Record/the-nature-and-economic-importance-of-nationalinnovations-systems-patel-parimal/10001166186

19. Pegkas, P., Staikouras, Ch., \& Tsamadias, C. (2019). Does research and development expenditure impact innovation? Evidence from the European Union countries. Journal of Policy Modeling, 41(5), 1005-1025. https://doi.org/10.1016/j.jpolmod.2019.07.001

20. Penn, A. S., Knight, Ch. J. K., Lloyd, D. J. B., Avitabile, D., Kok, K., Schiller, F., Woodward, A., Druckman, A., \& Basson, L. (2013). Participatory Development and Analysis of a Fuzzy Cognitive Map of the Establishment of a Bio-Based Economy in the Humber Region. PLoS One, 8(11). https://doi.org/10.1371/journal. pone.0078319

21. Petrunia, Y., Chentsov, V., Życzyński, N., \& Petrunia, V. (2019). Marketing environment and marketing management of universities in Ukraine: national and regional dominants. Innovative Marketing, 15(1), 1-12. http://dx.doi.org/10.21511/ im.15(1).2019.01

22. Radosevic, S., \& Petraite, M. (2006). The Role of Higher Education in National Innovation Systems in Central and Eastern Europe. Higher education in national innovation, Chapter 9, 35-60. Retrieved from https://www.researchgate.net/ publication/39065801_The_role_ of_higher_education_in_national_innovation_systems_in Central_and_Eastern_Europe
23. Ranga, M., \& Etzkowitz, H. (2013). Triple Helix Systems: An Analytical Framework for Innovation Policy and Practice in the Knowledge Society. Industry and Higher Education, 27(4), 237-262. https://doi. org/10.5367\%2Fihe.2013.0165

24. Smol, M., \& Kulczycka, J. (2019). Towards innovations development in the European raw material sector by evolution of the knowledge triangle. Resources Policy, 62, 453-462. Retrieved from https://doi.org/10.1016/j. resourpol.2019.04.006

25. Unger, M., \& Polt, W. (2017). The Knowledge Triangle between Research, Education and Innovation - A Conceptual Discussion. Foresight and STI Governance. Journal of the National Research University Higher School of Economics, 11(2), 10-26. Retrieved from https://foresight-journal.hse.ru/ data/2017/07/02/1171239631/2Polt-10-26.pdf

26. Vidal, R., Salmeron, J. L., Mena, A., \& Chulvi, V. (2015). Fuzzy Cognitive Map-based selection of TRIZ (Theory of Inventive Problem Solving) trends for ecoinnovation of ceramic industry products. Journal of Cleaner Production, 107, 202-214. https://doi. org/10.1016/j.jclepro.2015.04.131

27. Yatsukh, O. (2018). Cognitive modeling of factors of influence on the processes of formation and reproduction of fixed assets of agricultural enterprises. Development Management, 16(4), 73-87. http://dx.doi.org/10.21511/ dm.4(4).2018.07 